\title{
METODE CONDITIONAL AUTOREGRESSIVE DALAM ANALISIS PENYEBARAN KASUS PENYAKIT TUBERCULOSIS
}

\author{
Sandika S. Rajak ${ }^{1}$, Sumarno Ismail ${ }^{2}$, Resmawan ${ }^{3}$ \\ 1,2,3 Jurusan Matematika, Fakultas Matematika dan IPA, Universitas Negeri Gorontalo
}

e-mail: sandika.rajak@gmail.com

\begin{abstract}
Abstrak
Artikel ini membahas tentang penggunaan metode Conditional Autoregressive (CAR) untuk mengetahui faktor yang secara signifikan mempengaruhi kasus penyakit Tuberculosis (TBC) di Kota Gorontalo serta mengetahui pola penyebarannya. Metode yang digunakan adalah metode CAR yang bertujuan untuk mengetahui faktor yang secara signifikan mempengaruhi kasus penyakit TBC dan Indeks moran's bertujuan untuk mengetahui pola penyebarannya. Hasil penelitian memberikan kesimpulan bahwa jumlah penduduk miskin dan tinggi wilayah di Kota Gorontalo merupakan faktor yang secara signifikan mempengaruhi kasus penyakit TBC di Kota Gorontalo serta Pola penyebarannya mengindikasikan terjadinya proses autokorelasi spasial positif, artinya ada persamaan kategori antara masing-masing kelurahan.

Kata Kunci: Tuberculosis, Conditional Autoregressive, Indeks Moran's
\end{abstract}

\begin{abstract}
This research discusses the use of CAR model in finding out factors that significantly influence $T B C$ transmission and figuring out its transmission patterns in Gorontalo city. The methods apply CAR model aiming to discover factors that significantly influence TBC transmission and Moran's Index aiming to identify its transmission pattern Findings reveal that the number of impoverished population and highlands in Gorontalo city are factors that significantly influence disease transmission The transmission patterns also indicate positive spatial autocorrelation that signifies a similar category among sub-districts.

Keywords: Tuberculosis, Conditional Autoregressive, Index Moran's
\end{abstract}

\section{PENDAHULUAN}

Statistika adalah ilmu yang mengamati dan atau mengembangkan cara-cara pengumpulan data, pengolahan data, penganalisisannya sampai dengan penarikan kesimpulan (Sudjana 2015). Statistika dalam dunia kesehatan memiliki fungsi sebagai alat bantu monitoring program kesehatan untuk dilakukan analisis perbandingan dan mengetahui gambaran atau masalah-masalah kesehatan dengan data-data kuantitatif. Pada kasus TBC ilmu statistika digunakan untuk menganalisis faktor resiko beserta penyebarannya.

Tuberculosis adalah penyakit menular yang disebabkan oleh kuman TB (Mycobacterium Tuberculosis) yang menyerang paru, tetapi dapat juga menyerang organ tubuh lainnya. Dalam perspektif epidemiologi yang melihat kejadian penyakit sebagai hasil interaksi antar tiga faktor antara lain: penyebab (agent), kerentanan (host) dan lingkungan (environment) (Kemkes 2018). Data WHO menunjukkan bahwa pada tahun 2015, Indonesia termasuk dalam 6 besar negara dengan kasus baru TB terbanyak, dan pada tahun 2016 Indonesia menempati posisi kedua setelah India dengan beban tuberkulosis tertingi di dunia sesuai data WHO Global Tuberkulosis Report 2016.

Banyaknya kasus TBC pada suatu daerah pastinya memiliki kriteria berbeda, seperti pada kondisi geografis maupun hal-hal lain yang dapat mempengaruhi kejadian kasus TBC. Dalam ilmu statistika terdapat satu metode yang digunakan untuk menganalisis faktor resiko 
secara spasial yaitu metode Conditional Autoregressive (CAR). Menurut (Cressie 1993), CAR adalah model yang mengamati variabel acak pada setiap lokasi bersyarat tertentu yang ada di lokasi tetangga sekitarnya. Salah satu keunggulan dari metode CAR ini digunakan untuk pemetaan penyakit dengan memodelkan resiko relatif dan juga menggunakan informasi spasial untuk mengurangi kesalahan dari taksiran.

Metode CAR hingga saat ini masih banyak digunakan oleh beberapa peneliti dalam berbagai kasus, (Lee 2011) menggunakan metode conditional autoregressive untuk membandingkan model dengan Bayesian dalam pemetaan penyakit, (Ver Hoef et al. 2018) menjelaskan hubungan antara Conditional (CAR) dan Simultaneous (SAR) model Autoregressive pada kasus kejahatan. (Soroori et al. 2019) menggunakan metode conditional autoregressive lokal untuk pengembangan model prediksi zona kecelakaan dan identififikasi batas-batas resiko kecelakaan. (Dwi Hartanto et al. 2019) menggunakan metode spasial dalam analisis penyebaran kasus tuberkulosis Paru. (Mahading et al. 2020) menggunakan metode regresi spasial untuk mengetahui faktor-faktor yang mempengaruhi kerawanan wabah Demam Berdarah Dengue (DBD) di Kota Gorontalo. Banyaknya penelitian terkait CAR, menunjukkan bahwa metode ini masih efifisien digunakan untuk menemukan solusi dari berbagai kasus.

Pada makalah ini berisi inovasi terhadap Metode Conditional Autoregressive (CAR) yang diterapkan dalam menganalisis faktor-faktor yang memepengaruhi kasus penyakit TBC serta mengetahui pola penyebaran kasus penyakit TBC di Kota Gorontalo dengan menggunakan indeks Moran's.

\section{METODE PENELITIAN}

Penelitian ini dilakukan selama 5 bulan dimulai dari bulan April 2020 sampai bulan Agustus 2020. Data yang digunakan dalam penelitian ini merupakan data sekunder. Data tersebut didapatkan dari Dinas Kesehatan Kota Gorontalo dan Badan Pusat Statistik Kota Gorontalo. Sampel yang digunakan dalam penilitian ini adalah jumlah Kelurahan di Kota Gorontalo yang terkena kasus penyakit TBC. Analisis data yang dilakukan dalam penelitian ini adalah:

1. Uji asumsi normalitas.

Uji normalitas bertujuan untuk mengetahui apakah data yang telah dikumpulkan berdistribusi normal atau tidak. Uji normalitas yang dapat digunakan yaitu Kolmogorov Smirnov, Hipotesis yang digunakan dalam uji normalitas sebagi berikut:

$\mathrm{H}_{0}$ : residual berdistribusi normal

$\mathrm{H}_{1}$ : residual tidak berdistribusi normal

Dengan ketentuan, jika p-value $<\alpha=5 \%$ maka tolak H0.

2. Membuat matriks pembobot spasial $\mathrm{W}$ dengan nilai 0 atau 1 masing-masing unit.

Matriks pembobot spasial menggambarkan hubungan antar daerah. Setiap daerah diberi bobot 0 atau 1, nilai 0 artinya daerah i dan daerah $\mathrm{j}$ tidak bersebelahan sedangkan nilai 1 artinya daerah i dan daerah $\mathrm{j}$ berada bersebelahan. Hal ini menunjukkan bahwa baris pada matriks pembobot spasial menyatakan hubungan spasial suatu daerah dengan daerah lainnya, sehingga jumlah nilai pada baris ke- i merupakan jumlah tetangga yang dimiliki oleh daerah i.

3. Estimasi parameter model CAR

Estimasi parameter model CAR bertujuan untuk mengetahui nilai estimasi melalui proses interpretasi parameter dengan menggunakan rentang kesalahan yang minim.

4. Menentukan variabel yang signifikan

Menentukan variabel yang signifikan bertujuan untuk mengetahui variabel apa saja yang mempengaruhi kasus dengan nilai p-value lebih kecil dari nilai $\alpha$. 
5. Memetakan pola penyebaran kasus TBC berdasarkan variabel yang signifikan di Provinsi Gorontalo menggunakan indeks Moran's. Indeks moran's digunakan untuk mengetahui apakah satu wilayah memiliki hubungan atau autokorelasi antar wilayah lain, Hipotesis yang digunakan untuk mengetahui apakah terdapat autokorelasi pada setiap wilayah sebagai berikut:

$\mathrm{H} 0=$ Tidak ada autokorelasi antar lokasi

H1 = Terdapat autokorelasi antar lokasi

Pengambilan keputusan, $H 0$ ditolak apabila $\left|Z_{\text {Hitung }}\right|>Z \alpha / 2$ dengan $\alpha=10 \%$.

\section{HASIL DAN PEMBAHASAN}

\subsection{Uji Asumsi Normalitas}

Uji asumsi normalitas pada makalah ini digunakan untuk menentukan apakah data yang dikumpulkan berdistribusi normal atau tidak. Uji asumsi normalitas residual menggunakan uji Kolmogorov-Smirnov dengan bantuan software Minitab. Hasil uji asumsi normalitas bisa dilihat pada Gambar 1:

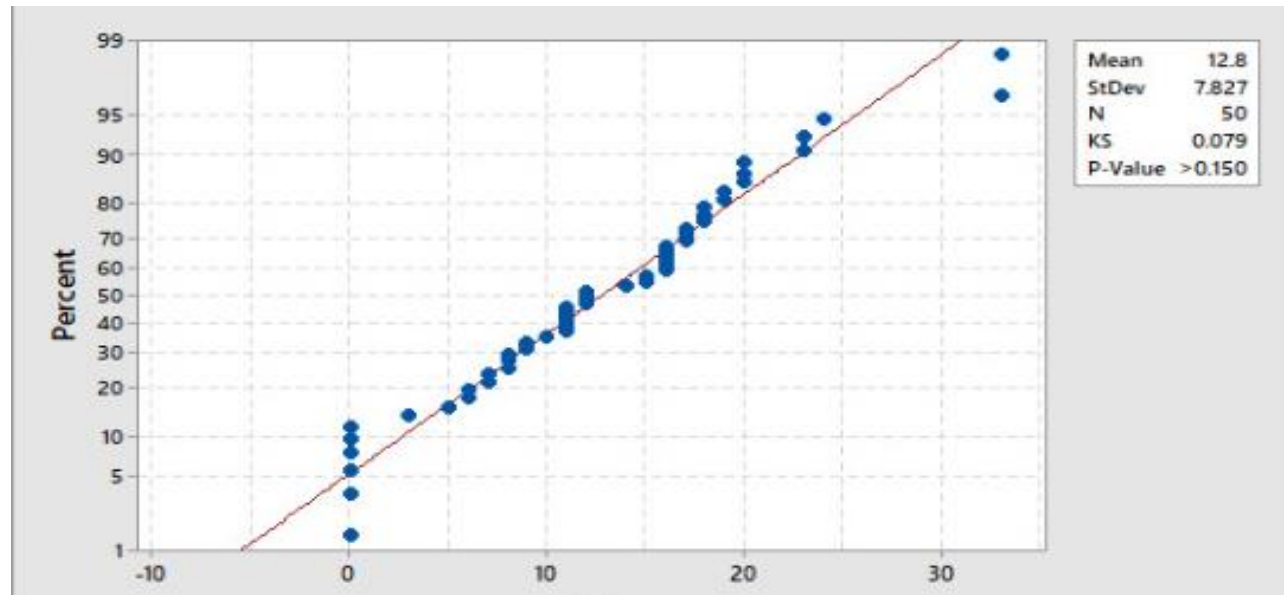

Gambar 1: Normalitas Residual

Gambar 1 menunjukkan bahwa nilai Kolmogorov-Smirnov sebesar 0.079 dan nilai p-value > $\alpha$ atau $0,150>0,05$ sehingga pengambilan keputusan yakni gagal tolak $\mathrm{H} 0$, artinya nilai residual berdistribusi normal.

\subsection{Matriks Pembobot Spasial}

Matriks pembobot spasial pada makalah ini digunakan untuk menggambarkan hubungan antar daerah. Kedekatan suatu daerah berdasarkan bobot yang diberikan. Penyusunan matriks pembobot spasial menggunakan metode Queen Continguity yang merupakan kombinasi dari persentuhan sisi wilayah dengan sisi wilayah lain yang bertetangga dan persentuhan titik sudut wilayah dengan sudut wilayah lain yang bertetangga. Pada Gambar 2 menunjukkan peta kedekatan suatu daerah dan hasil dari metode Queen Continguity. 


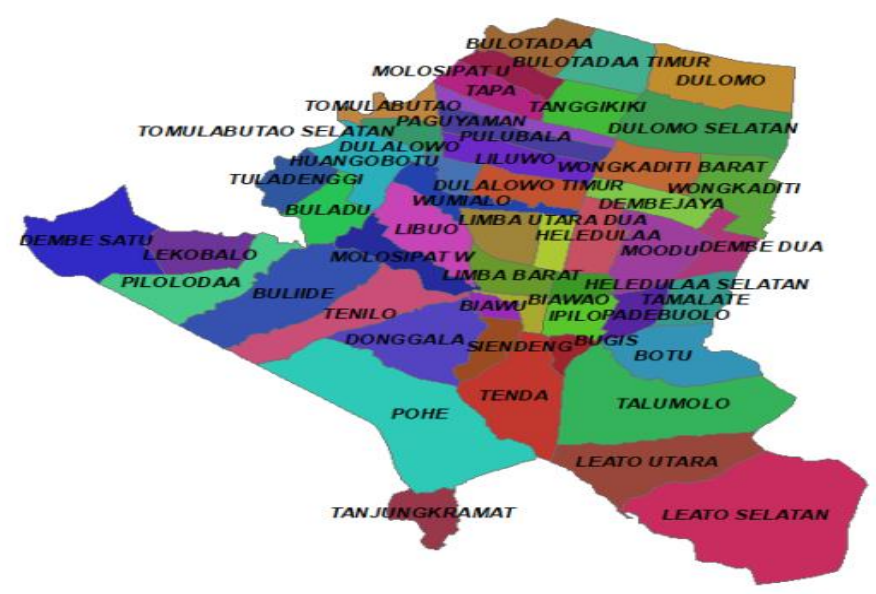

Gambar 2: Kedekatan suatu daerah

Nilai pengamatan yang diberikan untuk matriks pembobot spasial $\mathrm{W}$ :

$$
\mathrm{W}_{\mathrm{ij}}= \begin{cases}1 ; & \boldsymbol{i} \text { dan } \boldsymbol{j} \text { saling berdekatan } \\ 0 ; & \boldsymbol{i} \text { dan } \boldsymbol{j} \text { Tidak berdekatan }\end{cases}
$$

nilai 1 artinya daerah $\mathrm{i}$ dan daerah $\mathrm{j}$ berada bersebelahan sedangkan nilai 0 artinya daerah $\mathrm{i}$ dan daerah $\mathrm{j}$ tidak bersebelahan, untuk $\mathrm{i}$ dan $\mathrm{j}$ merupakan daerah yang diamati.

\subsection{Model Conditional Autoregressive (CAR)}

Model Conditional Autoregressive (CAR) pada makalah ini digunakan untuk mengetahui nilai estimasi dari setiap faktor yang diamati. Variabel yang digunakan terdiri dari empat variabel bebas dan satu variabel respon, yaitu X1 (Jumlah Penduduk), X2 (Jumlah Penduduk Miskin), X3 (Fasilitas Kesehatan) dan X4 (Tinggi Wilayah) terhadap variabel respon Y (Jumlah Kasus TBC). Hasil estimasi parameter CAR menggunakan bantuan software R disajikan pada Tabel 1.

Tabel 1: Estimasi parameter CAR

\begin{tabular}{|c|c|c|}
\cline { 2 - 3 } \multicolumn{1}{c|}{} & Estimate & $p$-value \\
\hline (Intercept) & 1,8857 & 0,5163 \\
\hline $\mathrm{X} 1$ & 0,0003 & 0,6217 \\
\hline $\mathrm{X} 2$ & 0,0120 & $2,065 \mathrm{E}-8$ \\
\hline $\mathrm{X} 3$ & 0,5071 & 0,5697 \\
\hline $\mathrm{X} 4$ & $-0,3639$ & 0,0033 \\
\hline
\end{tabular}

Dari Tabel 1, di peroleh model CAR:

$$
Z=1,8857+0,0003 X_{1}+0,0120 X_{2}+0,5071 X_{3}-0,3639 X_{4}
$$

Analisis CAR menunjukkan bahwa dari 4 variabel bebas yaitu X1 (Jumlah Penduduk), X2 (Jumlah Penduduk Miskin), X3 (Fasilitas Kesehatan) dan X4 (Tinggi Wilayah), terdapat 2 variabel bebas yang signifikan yakni X2 (Jumlah Penduduk Miskin) dan X4 (Tinggi Wilayah). Hal ini dapat dilihat berdasarkan Tabel 1. Nilai p-value dari variabel X2 dan X4 yang kurang dari $\alpha=10 \%$. Apabila variabel X2 (Jumlah Penduduk Miskin) bertambah sebesar satu satuan maka akan menyebabkan kenaikan presentase kasus 
TBC di Kota Gorontalo sebesar 0,0120 = 1,2\% dengan Variabel lain dianggap konstan. Apabila variabel X4 (Tinggi Wilayah) bertambah satu satuan maka akan menyebabkan penurunan presentase kasus TBC di Kota Gorontalo sebesar 0,3639 $=36 \%$ dengan variabel lain dianggap konstan.

\subsection{Indeks Moran's}

Indeks moran's pada makalah ini digunakan untuk mengetahui apakah satu wilayah memiliki hubungan atau autokorelasi antar wilayah lain. Hasil uji indeks moran's menggunakan bantuan software R disajikan dalam tabel 2 .

Tabel 2: Indeks Moran's

\begin{tabular}{|c|c|c|c|c|}
\hline Variabel & Moran's I & $\mathrm{I}_{0}$ & Variance & $\left|\mathrm{Z}_{\text {Hitung }}\right|$ \\
\hline $\mathrm{Y}$ & 0.09189 & $-0,0204$ & 0,00700 & 1,34212 \\
\hline $\mathrm{X} 2$ & 0,10425 & $-0,0204$ & 0,00694 & 1,49627 \\
\hline $\mathrm{X} 4$ & 0,40006 & $-0,0204$ & 0,00638 & 5,26398 \\
\hline
\end{tabular}

Tabel 2 menunjukkan hasil analisis $\left|Z_{\text {Hitung }}\right| \mathrm{Y}=1,34212, \quad \mathrm{X} 2=1,49627$ dan $\mathrm{X} 3=5,26398>\mathrm{Z} \alpha / 2=0.13$. Maka pengambilan keputusan adalah tolak H0 yang artinya terjadi autokorelasi antar lokasi. Nilai parameter indeks moran's sebesar $\mathrm{Y}=0,09189$, $\mathrm{X} 2=0,10425$ dan $\mathrm{X} 4=0,40006$ yang artinya nilai $0<\mathrm{I} \leq 1$ menunjukkan autokorelasi spasial positif atau membentuk klaster antar lokasi.

\subsubsection{Jumlah penduduk Miskin (X2)}

Hasil uji indeks moran's pada Tabel 2 untuk variabel jumlah penduduk miskin adalah 0,10425 hal ini menunjukkan nilai indeks moran's yang lebih besar dari 0 dan mendekati 1 membuktikan terjadi autokorelasi spasial positif atau pengelompokkan pada jumlah penduduk miskin. Pada Gambar 3 menunjukkan hasil moran's Scatterplot.

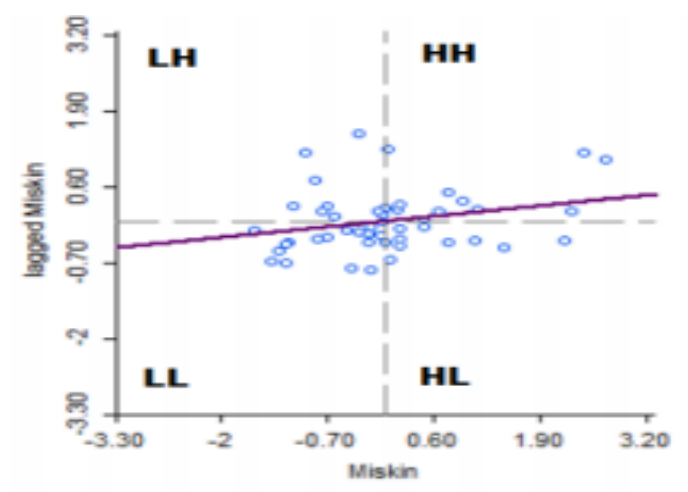

Gambar 3: Moran's Scatterplot Penduduk Miskin

Pada Gambar 3 menunjukkan hubungan spasial antar lokasi. Kuadran High-High (HH) terdapat pada kelurahan Leato Utara, hal ini mengindikasikan bahwa kelurahan tersebut memiliki nilai pengamatan yang tinggi. Kuadran Low-Low (LL) terdapat pada kelurahan Tanggikiki, Tapa, Paguyaman, Liluwo dan Pulubala, hal ini mengindikasikan bahwa kelurhan tersebut memiliki nilai amatan rendah bekelompok. Kuadran Low-High (LH) dan High-Low (HL) terdapat pada kelurahan Pilolodaa dan Limba Barat. hal ini 
mengindikasikan nilai amatan rendah dikelilingi nilai amatan tinggi dan nilai amatan tinggi dikelilingi nilai amatan rendah.

\subsubsection{Tinggi Wilayah (X4)}

Hasil uji indeks moran's pada Tabel 2 untuk variabel tinggi wilayah adalah 0,40006 hal ini menunjukkan nilai indeks moran's yang lebih besar dari 0 dan mendekati 1 membuktikan terjadi autokorelasi spasial positif atau pengelompokkan pada tinggi wilayah. Pada Gambar 4 menunjukkan hasil moran's Scatterplot tinggi wilayah.

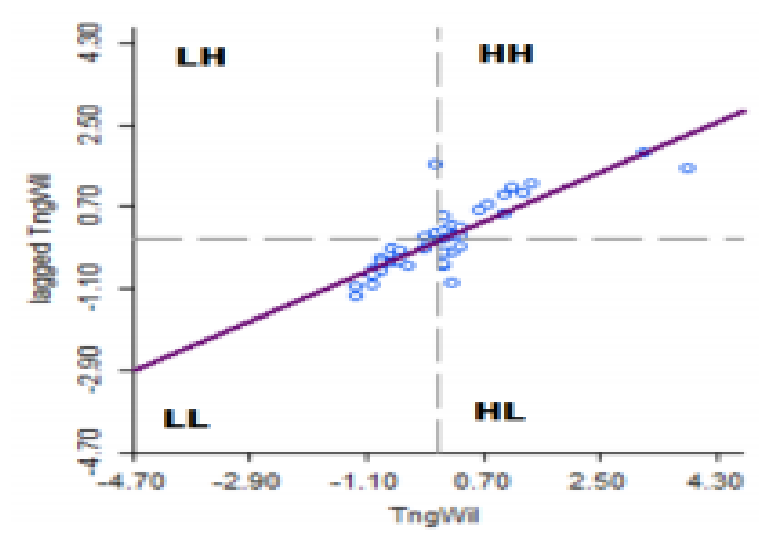

Gambar 4: Moran's Scatterplot Tinggi Wilayah

Pada Gambar 4 menunjukkan hubungan spasial antar lokasi. Kuadran High-High (HH) terdapat pada kelurahan Bulotadaa Timur, Dembe satu, Lekobalo, Molosipat Utara dan Tanggikiki, hal ini mengindikasikan bahwa wkelurahan tersebut memiliki nilai pengamatan yang tinggi. Kuadran Low-Low (LL) terdapat pada kelurahan Biawao, Biawu, Ipilo, Leato Selatan, Leato Utara, Limba Barat, Molosipat W, Pohe, Siendeng dan Tenda, hal ini mengindikasikan bahwa kelurahan tersebut memiliki nilai amatan rendah bekelompok. Kuadran High-Low (HL) terdapat pada kelurahan Donggala dan Heledulaa Selatan sedangkan Kuadran Low-High (LH) terdapat pada kelurahan Pilolodaa, hal ini mengindikasikan nilai amatan tinggi dikelilingi nilai amatan rendah dan nilai amatan rendah dikelilingi nilai amatan tinggi

\section{KESIMPULAN}

Metode Conditional Autoregressive (CAR) menyatakan bahwa faktor-faktor yang signifikan berpengaruh pada peningkatan kasus penyakit TBC di Kota Gorontalo adalah jumlah penduduk miskin dan tinggi wilayah Kota Gorontalo. Sedangkan Indeks moran's menyatakan Pola sebaran faktor yang secara signifikan mempengaruhi kasus penyakit TBC di Kota Gorontalo mengindikasikan terjadinya proses autorelasi spasial positif, artinya ada persamaan kategori antara masing-masing kelurahan.

\section{DAFTAR PUSTAKA}

Cressie, N. A. C. (1993), Statistics for Spatial Data, Statistics for Spatial Data, Wiley Series in Probability and Statistics, Hoboken, NJ, USA: John Wiley \& Sons, Inc. https://doi.org/10.1002/9781119115151.

Dwi Hartanto, T., Dian Saraswati, L., Sakundarno Adi, M., and Udiyono, A. (2019), ANALISIS SPASIAL PERSEBARAN KASUS TUBERKULOSIS PARU DI KOTA SEMARANG TAHUN 2018, Jurnal Kesehatan Masyarakat (Undip), Fakultas Kesehatan Masyarakat Universitas Diponegoro. 
Ver Hoef, J. M., Hanks, E. M., and Hooten, M. B. (2018), "On the relationship between conditional (CAR) and simultaneous (SAR) autoregressive models," Spatial Statistics, Elsevier B.V., 25, 68-85. https://doi.org/10.1016/j.spasta.2018.04.006.

Kemkes (2018), "Waspadai Peningkatan Penyakit Menular," Available athttps://www.kemkes.go.id/article/view/18030500005/waspadai-peningkatanpenyakit-menular.html.

Lee, D. (2011), "A comparison of conditional autoregressive models used in Bayesian disease mapping," Spatial and Spatio-temporal Epidemiology, Spat Spatiotemporal Epidemiol, 2, 79-89. https://doi.org/10.1016/j.sste.2011.03.001.

Mahading, T. S., Resmawan, R., Yahya, L., and Akolo, I. R. (2020), "Metode Spatial Autoregressive dalam Analisis Kerawanan Demam Berdarah Dengue di Kota Gorontalo," JMPM: Jurnal Matematika dan Pendidikan Matematika, 5, 9-19. https://doi.org/10.26594/JMPM.V5I2.1916.

Soroori, E., Mohammadzadeh Moghaddam, A., and Salehi, M. (2019), “Application of local conditional autoregressive models for development of zonal crash prediction models and identification of crash risk boundaries," Transportmetrica A: Transport Science, Taylor and Francis Ltd., 15, 1102-1123. https://doi.org/10.1080/23249935.2018.1564801.

Sudjana (2015), Metoda Statistika (7th Edition), Bandung: Tarsito Bandung. 